Farm animal welfare - who writes the rules?

Occasional Publication No. 23 - British Society of Animal Science 1999

edited by A. J. F. Russel, C. A. Morgan, C. J. Savory, M. C. Appleby and T. L. J. Lawrence

\title{
Animal health and welfare issues on organic livestock farms in the UK: results of a producer survey
}

\author{
S. Roderick, M. Hovi and N. Short \\ Veterinary Epidemiology and Economics Research Unit, Department of Agriculture, University of Reading, Earley Gate, \\ PO Box 236, Reading RG6 6AT
}

\section{Introduction}

Organic farming methods place paramount importance on the health and welfare of farm animals. Standards have been clearly established that put the needs of animals first. Although the proportion of organic farms in the UK occupies less than $0.5 \%$ of the total land area, a rapid increase in consumer demand is being partly met by an increase in the number of farms currently in a state of conversion. Standards for animal health management emphasize reduced dependence on prophylactic treatments, particularly antibiotics. The philosophy of organic farming emphasizes the need to produce food in an 'integrated, humane, environmentally and economically sustainable agricultural production system' (Lampkin and Measures, 1995). Concerns have been expressed about the potential impact on animal health and welfare (Andrews, 1991). Conversely, it has been argued that organic livestock systems offer opportunities to introduce improved husbandry methods that have long been recognized to be of general benefit to animal health and welfare (Vaarst, 1995). It has been suggested also that, while there has been a general increase in research into organic farming, little attention has been directed to animal health and welfare issues (Borgen, 1995). In 1995 a study of organic livestock systems in the UK was conducted with the objectives of describing health and welfare practices and identifying research priorities.

\section{Material and methods}

Postal questionnaires were sent to 270 Soil Association registered organic farmers. These contained questions relating to farm type and details of animal health practices for each livestock enterprise, including producer perception of disease. Open-ended questions referring to organic practices were also included. Producers' perceptions of disease was based on a subjective assessment of a range of common conditions, with respondents asked to score each from 1 (no problem) to 5 (serious problem).

\section{Results}

One hundred and sixty (59\%) questionnaires were returned, of which $139(52 \%)$ were considered to be useful returns. Most respondents kept more than one species of livestock, most commonly beef cattle and sheep.

\section{Dairy systems}

Thirty-four respondents kept dairy herds, of which $13(38 \%)$ had herds of more than 50 cows. The majority of farmers reared all their own replacement stock. The farms were evenly divided between those that wean calves at less than 1 week and those that wean at more than 1 week. A small minority removed calves after 12 weeks of age. The most important culling decisions were related to age $(37 \%)$, infertility $(37 \%)$ and mastitis history $(37 \%)$. A minority of farmers used routine prophylactic vaccinations against lungworm $(27 \%)$ or leptospirosis $(19 \%)$, with only one farmer using both. The majority of producers relied on clean grazing $(54 \%)$ and/or mixed grazing strategies $(50 \%)$ to control worms in young stock. Thirty-three percent used routine anthelmintic treatments. A small minority $(8 \%)$ did not use any of these strategies. Seventy-seven percent of dairy farmers used some form of footrot control strategy. The majority (62\%) adopted foot-trimming, with a third of these also using a footbath.

The highest problem-ranked disease was mastitis (Table 1). A combination of antibiotics (62\% of farms) and homeopathic remedies (65\% of farms) were used to treat mastitis. Approximately a quarter of producers were using cold water massage with $19 \%$ using uddermint. All conditions pertaining to calf and heifer rearing received a low average ranking with little difference between diseases. Some conditions, such as lungworm respiratory diseases did receive high rankings on individual farms.

\section{Beef systems}

A total population of 8506 beef animals were surveyed on 112 farms. Eighty-nine percent of farms were single suckler units, $13 \%$ had multiple-suckler 
Table 1 Farmer perception of animal health problems in organic farms: dairy cows (23 herds)

\begin{tabular}{|c|c|c|c|c|c|c|}
\hline \multirow[b]{2}{*}{ Disease } & \multirow[b]{2}{*}{ Average score } & \multicolumn{5}{|c|}{ Distribution of score (\%) } \\
\hline & & No problem & Not common & Slight problem & Occasional problem & Serious problem \\
\hline Mastitis & $3 \cdot 3$ & 4 & 15 & 52 & 26 & 4 \\
\hline Infertility & $2 \cdot 7$ & 11 & 33 & 41 & 11 & 4 \\
\hline Lameness & $2 \cdot 4$ & 22 & 41 & 30 & 7 & 0 \\
\hline Milk fever & $2 \cdot 3$ & 11 & 52 & 30 & 7 & 0 \\
\hline Calving problems & 1.9 & 41 & 44 & 15 & 0 & 0 \\
\hline Abortion & $1 \cdot 7$ & 56 & 33 & 4 & 7 & 0 \\
\hline BSE & $1 \cdot 6$ & 67 & 22 & 7 & 4 & 0 \\
\hline Bloat & $1 \cdot 5$ & 59 & 26 & 15 & 0 & 0 \\
\hline Ketosis & $1 \cdot 4$ & 59 & 37 & 4 & 0 & 0 \\
\hline Grass staggers & $1 \cdot 3$ & 81 & 7 & 7 & 4 & 0 \\
\hline
\end{tabular}

Key for disease perception score: $1=$ no problem; $2=$ not common; $3=$ slight problem; $4=$ continuous problem; $5=$ serious problem.

systems and $10 \%$ bucket-reared calves. Many also kept sheep and the majority $(46 \%)$ practised mixed or clean $(61 \%)$ grazing to control internal parasites. Twenty-eight percent of beef producers used anthelmintics, mainly integrated with controlled grazing practices. Generally, health issues among adult beef animals were not given high problem rankings (Table 2). External parasites, diarrhoea and mineral deficiencies, although receiving low rankings, were considered the most important conditions in young, growing stock.

\section{Sheep systems}

Sixty-four percent of the 90 sheep systems covered were classed as lowland, $19 \%$ were upland and $11 \%$ were hill flocks. A small percentage operated a combination of these. The farms were evenly divided into those lambing outdoors, indoors and both. Most flocks were wintered outdoors. Thirty-eight percent of farms sold lambs direct to an abbatoir, $32 \%$ through a livestock auction, $21 \%$ via farm shop and
$28 \%$ through unspecified means. Cull ewes were generally sold through traditional auction yards $(62 \%)$. Forty-one percent of the farmers surveyed vaccinated against clostridial diseases and $28 \%$ against pasteurella. A number of these $(24 \%)$ used both vaccination regimes. The majority $(64 \%)$ used anthelmintics, to varying degrees. Many of these were using anthelmintics in combination with other methods. Sixty-nine percent used clean grazing practices and $55 \%$ mixed grazing. A proportion was obviously using a combination of these methods. Six percent of farmers were using homeopathic remedies to control worms. The use of garlic was also common. Only $2 \%$ responded that they did not have a control policy. Almost half of organic farmers (48\%) either used anthelmintics on lambs infrequently or never. Thirty-two percent wormed every 3 to 6 months, whilst $12 \%$ wormed every 2 months and $8 \%$ wormed every month. Footrot was perceived to be the most important adult sheep condition (Table 3). Twenty percent felt that this was

Table 2 Farmer perception of animal health problems in organic suckler beef herds ( 89 herds)

\begin{tabular}{lcccccc}
\hline & & \multicolumn{3}{c}{ Distribution of score (\%) } \\
\cline { 3 - 7 } Disease & Average score & No problem & Not common & Slight problem & Occasional problem & Serious problem \\
\hline Infertility & 1.9 & 40 & 37 & 18 & 5 & 0 \\
Calving difficulties & 1.8 & 43 & 37 & 17 & 2 & 1 \\
Mastitis & 1.7 & 52 & 32 & 14 & 0 & 1 \\
Lameness & 1.6 & 53 & 33 & 13 & $\mathbf{1}$ & 0 \\
Grass staggers & 1.3 & 77 & 15 & 7 & 0 & 0 \\
Fluke & 1.2 & 84 & 8 & 2 & 0 & 0 \\
Bloat & 1.2 & 83 & 15 & 7 & 0 & 1 \\
BSE & 1.1 & 92 & 7 & & 0 \\
\hline \hline
\end{tabular}

Key for disease perception score: $1=$ no problem; $2=$ not common; $3=$ slight problem; $4=$ continuous problem; $5=$ serious problem. 
Table 3 Farmer perception of animal health problems in organic sheep flocks: breeding ewes (85 flocks)

\begin{tabular}{|c|c|c|c|c|c|c|}
\hline \multirow[b]{2}{*}{ Disease } & \multirow[b]{2}{*}{ Average score } & \multicolumn{4}{|c|}{ Distribution of score (\%) } & \multirow[b]{2}{*}{ Serious problem } \\
\hline & & No problem & Not common & Slight problem & Occasional problem & \\
\hline Footrot & $2 \cdot 7$ & 14 & 30 & 29 & 23 & 5 \\
\hline Mastitis & $2 \cdot 1$ & 23 & 47 & 28 & 2 & 0 \\
\hline Fly strike & $2 \cdot 1$ & 26 & 43 & 26 & 5 & 1 \\
\hline Fluke/worms & $2 \cdot 0$ & 37 & 29 & 27 & 7 & 0 \\
\hline Lambing difficulties & 1.9 & 29 & 45 & 26 & 0 & 0 \\
\hline Twin lamb disease & 1.7 & 46 & 38 & 16 & 0 & 0 \\
\hline Clostridial diseases & $1 \cdot 6$ & 62 & 21 & 13 & 4 & 0 \\
\hline Pasteurella & 1.5 & 63 & 27 & 5 & 4 & 1 \\
\hline Abortion & 1.5 & 70 & 17 & 12 & 1 & 0 \\
\hline Sheep scab & $1 \cdot 2$ & 90 & 5 & 2 & 2 & 0 \\
\hline Scrapie & $1 \cdot 1$ & 95 & 1 & 4 & 0 & 0 \\
\hline
\end{tabular}

Key for disease perception score: 1 = no problem; 2 = not common; $3=$ slight problem; $4=$ continuous problem; $5=$ serious problem.

a continuous problem. The majority used either footbaths, foot trimming or a combination of the two for control. Antibiotics were not widely used. Of the diseases afflicting lambs, fly strike, worms and footrot received the highest rankings, although overall these were perceived as slight problems. Eleven percent did, however, regard fly strike as a continuous problem and $8 \%$ gave worms a similar ranking. The problem of fly strike was mainly tackled by a combination of the use of cyromazine (Vetrazin; Novartis) and management techniques such as dagging. There were too few goats covered in the survey to allow any meaningful analysis.

\section{Pig systems}

Only 24 organic pig farmers with a total of 6250 pigs responded to the questionnaire. More than half of these were kept on one farm. Most of the herds were classified as mixed breeding and fattening units, with pigs predominantly housed outdoors in arcs. The main outputs from these farms were pork and bacon weight animals for slaughter. A small sample and large between farm variation rendered data reflecting disease perception as less meaningful than data from ruminant systems. Lice infestation was the only condition given a mean ranking suggesting a slight problem. Disease control trends were of low inputs of chemotherapy and chemoprophylactic treatments.

\section{Poultry systems}

Only eight broiler producers responded, one of which had 5000 birds, accounting for $87 \%$ of the total broiler population. The mean flock size of the other seven producers was only 11 birds. Forty-seven respondents indicated that they kept laying hens. The average laying flock size was 42 hens. Only 22 producers completed detailed health and management questions and therefore only a limited analysis of organic poultry was possible. The trends were of low disease ranking and veterinary inputs.

\section{Discussion}

Generally, organic farmers do not perceive animal health issues as a major problem on their farms. The most significant disease problems identified by organic farmers are similar to those commonly seen in conventional systems. The view that organic farming constitutes a welfare concern was not the perception of the producers. The common misconception of organic farming being mainly reliant on 'alternative' medicines without the use of conventional veterinary inputs was not borne out by the results of this study. What was evident is that there is a reliance on a reduced input of the veterinary services combined with integrated alternative treatments and appropriate husbandry. A number of producers commented that they would like more practical information on homeopathy from veterinarians trained in its use.

Many of the comments received were concerned with welfare issues, particularly those pertaining to housing and transport. There was particular concern with regards to a marketing and infra-structure that limit the achievement of high welfare standards. A fundamental component of the organic philosophy relates to the avoidance of animal suffering. The Soil Association (1989) states 'if, despite appropriate and humane husbandry, animals fall ill and drug use is deemed necessary, it must not be withheld'. Respondents frequently commented on the importance of this flexibility in organic standards as 
a rigid set of rules may have some negative welfare impact.

\section{Acknowledgements}

We would like to thank the Animal Health Trust for supporting this study.

\section{References}

Andrews, T. 1991. Suffering animals in a green landscape. Dairy Farmer 38: 26-28.
Borgen, M. 1995. Ecoguide 1995/96. Organic Service Centre, Copenhagen.

Lampkin, N. and Measures, M. 1995. Organic farm management handbook 1995/96. University of Wales, Aberystwyth.

Soil Association 1989. Organic farming and animal welfare. Soil Association, Bristol.

Vaarst, M. 1995. Sundhed og sygdomshadtering I danske okologiske malkekvaebesaetninger. Ph.D. thesis. The Royal Veterinary and Agricultural School, Copenhagen. 